\title{
"The New Pandemic Challenge in Dentistry" Ozone in Aerosol Free Dental Procedures Post COVID 19 - A Review Article
}

\author{
Sahana Sadasivam ${ }^{1}$, Geeta IB ${ }^{2}$ \\ 1, 2 Department of Conservative Dentistry and Endodontics, Rajarajeswari Dental College, Bangalore, India.
}

\section{ABSTRACT}

The world health organization declared the outbreak of Corona virus as a public health emergency of international concern on $30^{\text {th }}$ January 2020 . The disease is transmitted by inhalation or contact with infected droplets and the incubation period ranges from 2 to 14 days. This mode of transmission has led to a concern for dentists worldwide. Due to the characteristics of dental settings, the risk of cross infection can be high between patients and dental practitioners. Various modifications in treatment options have been investigated to reduce the release of aerosols and minimize patient and dentist exposure.

These modifications in the dental set up are incorporated to protect the practitioner and the patient from cross contamination. One such treatment modality in reducing aerosol production is the use of Ozone. Ozone is an allotropic form of oxygen and has been used successfully in the treatment of various diseases for over a hundred years. It has a high oxidation potential and is 1.5 times greater than chlorine when it is used as an antimicrobial agent. It has also shown to stimulate remineralization and has hence led to its increasing popularity and demand in the dental field.

Its unique properties include analgesic, antimicrobial and antihypnotic actions. Its atraumatic, painless, non-invasive, and relative absence of discomfort and side effects has led to its use in dentistry with increased patient's acceptability and compliance thus making it an ideal choice for various treatment options in dentistry which would eventually lead to reduced aerosol exposure. This review is an attempt to highlight various treatment modalities of Ozone therapy during post Covid-19 scenario in dental practices and its possible clinical applications in future.

\section{KEY WORDS}

Covid-19, Ozone Therapy, Dental Practice
Corresponding Author:

Dr. Geeta IB.,

Department of Conservative

Dentistry and Endodontics

Rajarajeswari Dental College,

Bangalore, India.

Email ID:geeta.sanjeev@gmail.com

DOI: $10.14260 / \mathrm{jemds} / 2021 / 475$

How to Cite This Article:

Sadasivam S, Geeta IB. "The new pandemic challenge in dentistry" ozone in aerosol free dental procedures post covid-19 - a review article. $J$ Evolution Med Dent Sci 2021;10(30):2325-2330, 10.14260/jemds/2021/475

Submission 10-08-2020, Peer Review 06-07-2021, Acceptance 12-07-2021, Published 26-07-2021.

Copyright (C) 2021 Sadasivam S. et al. This is an open access article distributed under Creative Commons Attribution License [Attribution 4.0 International (CC BY 4.0)] 


\section{BACKGROUND}

Many dental procedures produce droplets and aerosols that are contaminated with blood and micro-organisms. Production of airborne material during dental procedures is obvious to the dentist, the patient and the dental team. The aerosol cloud is evident during cavity preparation or tooth preparation with an airotor, rotary instrument or air abrasion, during the use of an air water / 3 - way syringe, an ultrasonic scaler, air polishing etc. This ubiquitous aerosolized cloud is a combination of different materials originating from the treatment site and from various dental unit waterlines. ${ }^{1}$ Infectious aerosol can cause illness and is composed of two types of aerosols: Dust borne or droplet nuclei, dust borne aerosols are larger in diameter. They are easily eliminated from the air by filtration or sedimentation and are less likely to carry microbes that cause illnesses. These specific aerosols are not seen as a direct threat to infection control. Droplet nuclei, however, are smaller in size and settle out of the air slowly. These can be easily spread throughout the dental operatory by air currents, which can lead to contamination of the atmosphere. Droplet nuclei particles can remain in the environment for long periods of time, which make them a greater threat to the patient and health care provider. ${ }^{2}$ With the onset of severe acute respiratory syndrome coronavirus 2 (SARS-CoV-2), which was initially named as novel coronavirus or 2019-nCoV, questions concerning the potential for the spread of infections from this aerosol may arise. ${ }^{3}$ Hence an alternative to reduce the production of aerosols in a dental setup can be the use of ozone therapy in various applications of dental practice.

\section{OZONE}

A molecule consisting of three atoms of oxygen which is derived from a higher energetic form of atmospheric oxygen, also known as trioxygen or triatomic oxygen is called ozone $\left(\mathrm{O}_{3}\right)$. The word Ozone is derived from Greek literature called "Ozein" which originally means odorant. ${ }^{4}$

\section{Mechanism of Action}

The atmosphere is made up of various layers and one of which is the stratosphere which is rich in ozone. In the stratosphere (which is the second layer of the atmosphere above the troposphere) when a high energy ultraviolet radiation hits an oxygen molecule, it splits into two free oxygen atoms, these free oxygen atoms collide with the other oxygen molecules leading to the production of ozone $\left[\mathrm{O}_{3}\right]$. It swiftly gives up nascent oxygen [0] molecule to form oxygen gas, hence it is considered as an unstable gas. Due to this instability, it has the highest oxidation potential. This strong oxidant property of the ozone gas has led to the use of ozone in various medical and dental fields.

\section{Ozone Generating Systems \\ Ultraviolet System}

(UV light in the range from $160-240 \mathrm{~nm}$ ) - This will create ozone from oxygen. Ozone is created by photolysis of the oxygen molecule $\left(\mathrm{O}_{2}\right)$. This will disrupt the molecule and create valent oxygen atoms $(0)$ which will then attach to any individual oxygen molecules $\left(\mathrm{O}_{2}\right)$ to produce ozone $\left(\mathrm{O}_{3}\right)$.

Cold Plasma System (Dielectric Barrier Discharge) When the plasma is formed oxygen, molecules are split into single oxygen atoms which then recombine with 0xygen $\left(\mathrm{O}_{2}\right)$ and forms ozone $\left(\mathrm{O}_{3}\right)$. Cold plasma ozone generators utilize oxygen as the input source, and they are used to produce ozone with a concentration of about 5 - $7 \%$. In this system, an electrostatic field is created as the voltage jumps between the anode and the cathode rods. Air and water purification are the applications of this system.

\section{Corona Discharge System}

Any electrical discharge, or spark will create ozone. The spark will divide the oxygen molecule $\left.\mathrm{O}_{2}\right)$ found in ambient air into elemental oxygen (0). These oxygen atoms will quickly bind to another oxygen molecule $\left(\mathrm{O}_{2}\right)$ to form ozone $\left(\mathrm{O}_{3}\right)$. This system gives rise to a high concentration of ozone as a direct result of power dissipation. In a corona discharge ozone generator, the electrical discharge will take place in an air gap within the corona cell designed specifically to split the oxygen molecule and produce ozone. In this air gap a dielectric is used to distribute the electron flow evenly across this gap to spread the electron flow to a greater volume of oxygen as possible. It is easy to operate this design of the ozone generating system as the ozone production rate can be controlled, hence most used in the dental and medical fields.

\section{Forms of Ozone Available for Dental Application \\ Gaseous form}

Ozone generating equipment converts oxygen $\left(\mathrm{O}_{2}\right)$ to ozone $\left(\mathrm{O}_{3}\right)$. The ozone is then led to a hand piece fitted with a silicone cup. Different shapes of silicone cups are available that correspond to the form of various teeth and their surfaces. This ensures close contact between the silicone cup and the carious area of the tooth so that the ozone does not escape. The ozone is led through the silicone cup over the tooth for a minimum of 10 seconds. The ozone in the silicone cup is collected again and reconverted to oxygen by the apparatus. ${ }^{4}$ Gaseous ozone could be discharged topically either by a sealing suction system or an open system to avoid inhalation and adverse effects. Most frequently this form of ozone is used in endodontics and restorative dentistry. It is a non invasive therapy for treatment of dental caries and may be used as a disinfectant before the placement of a direct restoration. The minimum application time for the gaseous form to be effective against the microbes is 3 minutes.

\section{Ozonated water}

It has been shown to be effective against various microbes including the Gram-positive and Gram-negative oral microorganisms as well as bacteria in plaque biofilm. It is cost effective in comparison to other chemical cleaners. ${ }^{5,6}$ 
The aqueous form of ozone is less effective against microbes than the gaseous form ozone when used as a dental disinfectant. ${ }^{7}$ If ozone gas is inhaled into the respiratory tract 8 it has few toxic effects, hence to control oral infections and various pathogens, ozonated water may be useful. ${ }^{9}$ Commercially available as, ultra - pure, triple ozone treatment system.

\section{Ozonized Oil}

Ozonated oils are pure plant extracts, through which pure oxygen and ozone are passed. The plant extracts undergo a chemical reaction to form a thick, viscous oil, and in some cases, a petroleum jelly like product. The final products contain ozonides. This method of external application is harmless. ${ }^{10}$ It is a competitive antimicrobial agent. It is easily available due to wide availability and accessibility of sunflower oil. It is found efficacious against streptococci, staphylococci, enterococci, Escherichia coli, pseudomonas, and especially mycobacteria and is used for the cure of fungal infections. Commercially available as bioperoxoil, oleozone.

\section{OZONE GENERATING SYSTEMS} USED IN DENTISTRY

\section{Healozone}

The newest generation of HealOzone known as the healOzone $\mathrm{X} 4$ is known to deliver higher ozone concentrations, thus taking disinfection in dentistry to a next level. Ozone has been already used as a powerful disinfectant in medicine for a decade because of which it is known as the ultimate disinfection chemical. Higher doses of ozone can be used in many dental applications. It penetrates even to the smallest pit and fissures of the teeth to destroy microorganisms including viruses, bacteria, and fungi. Ozone is a gas that is very efficacious against bacteria in and on the teeth. The HealOzone $\mathrm{X} 4$ unit produces ozone from oxygen by one of the two methods:

\section{Mechanism of Action}

HealOzone X4 unit can produce ozone from oxygen in the ambient air (Low dosage mode) or from pure oxygen supplied by an oxygen bottle (High dosage mode). The latter method generates higher concentrations of ozone gas. The HealOzone $\mathrm{X} 4$ uses high voltage to convert oxygen into ozone. The ozone that is generated by the machine is channelled through the hand piece to the affected tooth or root canals to treat the carious lesions. After treatment, the ozone gas is suctioned off, dried, and converted back into oxygen by the ozone neutralizer.

Parts of a Healozone
1. Oxygen supply
2. Air dryer
3. Air supply
4. Ozone
5. Ozone generator
6. Ozone neutraliser
7. Tooth cup
8. Hand piece
9. Moisture trap

\section{Prozone}

W\&H's ozone generator has been available to dentists worldwide since 2008. Despite its sterilisable ergonomically designed handpiece, it features pre-set, predefined treatment times which make it easy to manage, the company states. Prozone is suitable for a wide range of dental applications including cavity, root canal, surgical disinfection as well as periodontal and endodontic treatment. Devices utilizing ozone technology such as Prozone expose filtered air to a high electrical voltage which is directly applied to the treatment area where it destroys bacteria and viruses through oxidation.

\section{Ozotop}

It is a compact, handy table top unit having a free flow ozone delivery system which utilizes corona discharge. Root canals and periodontal pockets could be easily penetrated through this device. In this system, air in the atmosphere is utilized that is filtered and dried before it is passed over a ceramic plate, later a high voltage is applied which then finally produces ozone. As this is an open system, high volume suction is mandatory. ${ }^{11}$ Depending on the requirement of treatment, ozone is applied at 6,12,18, 24 seconds (e.g., $12 \mathrm{~s}$ - surgical disinfection, $18 \mathrm{~s}$ - periodontal disinfection).

\section{Ozony Tron}

This appliance uses the principle of high frequency and voltage. With the current strength, five different levels of adjustment of ozone concentration could be done. It consists of a double glass camera which forms the glass probe. This glass probe consists of a mixture of noble gases which conducts and emits electromagnetic energy. As the tip of the probe gets in contact with the body, energy is emitted which causes splitting of environmental diatomic oxygen into singular atomic oxygen and ozone. Ozone concentration in the operation field using this unit is $10-100 \mu \mathrm{g} / \mathrm{ml}$. Therefore, ozone could be applied to the areas that are difficult to reach and inaccessible such as gingival pockets or root canals, as there is no closed circuit there. The cost ranges between Rs. 13,000 and Rs. $15,000 .^{12}$

\section{Prevention of Dental Caries}

Dental caries is a bacterially mediated disease characterised by demineralisation of the tooth surface, which may lead to cavitation, discomfort, pain and eventual tooth loss. Ozone is toxic to certain bacteria in vitro and it has been suggested that delivering ozone into a carious lesion might reduce the number of cariogenic bacteria. This possibly could arrest the progress of the lesion and may, in the presence of fluoride, perhaps allows remineralisation to occur. This may in turn delay or prevent the need for traditional dental conservation by 'drilling and filling'. The application of ozone therapy in the treatment of dental caries is extensively studied and many studies have proved its effectiveness in the treatment of pit and fissure caries, root caries and interproximal caries.

Holmes ${ }^{13}$ assessed the effect of an ozone delivery system, combined with the daily use of a remineralizing patient kit, on the clinical severity of non-cavitated leathery primary root carious lesions (PRCLs), in an older population group. He concluded that dentistry has the ability to reverse lesions with just 40 seconds of ozone treatment. At 18 months, $100 \%$ 
reversal and remineralization had been achieved. Leathery noncavitated primary root caries can be arrested non operatively using ozone and remineralizing products. It is suggested that this treatment regime is an effective alternative to conventional drilling and filling.

Baysan and Lynch ${ }^{14}$ have evaluated the effect of ozone on the microbial flora and clinical severity of primary root caries in-vivo. A biopsy was taken from half of each lesion prior to and after ozone application, and the microbiological counts were determined and compared. The authors reported that ozone application for either 10 or 20 seconds dramatically reduced most of the microorganisms in primary root caries lesions without any side effects recorded at recall intervals between 3 months and 5.5 months.

In an in-vivo setting, the efficiency of either ozone alone or combined with a remineralizing solution following application on initial pit and fissure caries in permanent molars was evaluated. After ozone treatment (40 s), patients either using the remineralizing solution or not were followed up at 1 month, 2 months, 3 months, and 6 months. The results have shown that use of remineralizing solution had no additional effect on the remineralization of initial pit and fissure caries lesions treated with ozone. The authors concluded that ozone treatment either alone or combined with a remineralizing solution was found to be effective for the remineralization of initial fissure caries lesions. ${ }^{15}$

\section{Method of Application}

Ozone is delivered through a hand piece, which is equipped with a silicon cup. The cup is applied directly to the tooth so that it forms a tight seal at the application site. The mechanism of action is due to its microbiological properties and its ability to oxidize the bacterial cell wall.7,8 Pyruvic acids, that is produced by bacteria and implicated in the progression of caries, is oxidized by Ozone to acetate and Carbon dioxide. This treatment is an alternative therapy to conventional drilling and filling for non cavitated deciduous carious lesion. The infusion of ozone into non carious dentin prevented biofilm formation invitro from S. Mutans and Lactobacillus acidophilus over a 4-week period". ${ }^{16}$

\section{AREAS OF DENTISTRY WHERE OZONE TREATMENT CAN REPLACE AEROSOLS}

\section{Ozone in the Field of Periodontics}

Ozone has been suggested as an adjunct antiseptic in periodontitis therapy. P. gingivalis, T. forsythia and P. micra could be eliminated by $2 \%$ Chlorhexidine or by ozone gas. Nagayoshi et al. (2004) tested the efficacy of ozonated water on survival and permeability of oral microorganisms and dental plaque. They confirmed that ozonated water $0.5-4 \mathrm{mg}$ ( l) was highly effective in killing both the microorganisms. Huth et al. (2006 - 2007) in their study declared that the aqueous form of ozone, as a potential antiseptic agent, showed less cytotoxicity than gaseous ozone or established antimicrobials under most conditions. ${ }^{17}$ Nagayoshi et al. ${ }^{18}$ examined the effect of ozonated water on oral microorganisms and dental plaque. Dental plaque samples were treated with 4 $\mathrm{mL}$ of ozonated water for 10 seconds. They observed that ozonated water was effective for killing gram-positive and gram-negative oral microorganisms and oral Candida albicans in pure culture as well as bacteria in plaque biofilm and therefore might be useful to control oral infectious microorganisms in dental plaque. Nagayoshi et al. tested the efficacy of three different concentrations of ozone water 0.5 , 2 , and $4 \mathrm{mg} / \mathrm{ml}$ in distilled water) on the time dependent inactivation of cariogenic, periodontopathogenic and endodontopathogenic microbes (streptococcus, Porphyromonas gingivalis and P. endodontalis, actinomyces, actinomycetemcomitans, Candida albicans) in culture and in biofilms. They confirmed that ozonated water was highly effective in killing of both gram positive and gram-negative microorganisms.

\section{Ozone in Pedodontics}

The provision of dental treatment for young children can have long lasting effects. As all dentists know, at this stage restorative care tends to be more difficult, more extensive and has increased cost implications. The use of ozone and mineral releasing glass ionomers can play a significant role in the dental management of such child patients. Treatment of caries with ozone is simple, fast and involves little preparatory work. The loose debris is first cleaned away, until a leathery base is reached which can be done with hand instruments. Ozone is applied, the lesion is wetted with the CurOzone (CurOzone Canada Inc) remineralising wash and then the glass ionomer is applied. ${ }^{19}$ Most of the children have fear and anxiety towards dental procedures. Dahnhart JE et al. ${ }^{20}$ evaluated the anxiety levels of children (and their parents) treated with ozone and found that all children \& parents reported significant anxiety prior to ozone treatment. However, following the treatment, the children reported that they would be pleased to return for future treatments. Also, $80 \%$ of the parents said they would be willing to pay more for this therapy compared with traditional drilling and filling.

\section{Ozone in Oral Surgery}

Ozone therapy has a vast range of applications in oral surgery because of its biological properties such as enhancing wound healing, improving several properties of erythrocytes, and facilitating oxygen release in the tissues. All these biological events cause and hence improve the blood supply to the ischemic zones leading to use of ozone in case of woundhealing impairments, following surgical interventions like tooth extractions or implant dentistry. ${ }^{21,22}$

Ahmedi et al. ${ }^{23}$ evaluated the efficacy of ozone gas in the reduction of dry socket, which occurred after surgical extraction of lower jaw third molars. Two groups were evaluated: in the control group, saline solution was used for irrigation of extraction sockets and, intraalveolar ozone was applied at $12 \mathrm{~s}$ (Prozone, W\&H, UK) in the experimental group. They concluded that the ozone gas had a positive effect in reducing the development of dry socket and pain following third molar surgery depending on metabolic capabilities of ozone for promoting haemostasis, increasing the supply of oxygen, and inhibiting bacterial proliferation.

\section{Ozone in Prosthodontics}

Dentures are commonly inhabited by microbial plaque, such as Candida albicans. Denture stomatitis is commonly 
encountered in clinical practices, which can be prevented by effective denture plaque control. One successful method to do so is the use of ozone as a disinfecting agent to clean the denture. Arita et al. ${ }^{24}$ concluded that exposure of dentures to flowing ozonated water ( 2 or $4 \mathrm{mg} / \mathrm{l}$ ) for $1 \mathrm{~min}$ can reduce the number of Candida albicans.

\section{Role of Ozone in Sterilization}

Ozone has been used for years as a drinking water disinfectant. Ozone consists of Oxygen $\left(\mathrm{O}_{2}\right)$ with a loosely bonded third oxygen atom that is readily available to attach to, and oxidize, other molecules. This additional oxygen atom makes ozone a powerful oxidant that destroys microorganisms but is highly unstable (i.e., half - life of 22 minutes at room temperature). Ozone gas is a highly effective surface disinfectant for instruments, implants, and prostheses. The solubility of ozone in water $\left(50 \mathrm{ml}\right.$ ozone in $100 \mathrm{ml}$ water at $\left.0{ }^{\circ} \mathrm{C}\right)$ is ten times greater than that of oxygen. The half - life of ozone ranges from 1 hour at $22{ }^{\circ} \mathrm{C}$ to approx. 3 hours at $4{ }^{\circ} \mathrm{C}$, when doubledistilled water is used as a solvent. Ozone sterilization is also compatible with stainless steel instruments. Ozone Sterilization is the latest low temperature sterilization method introduced and is suitable for many heat sensitive and moisture sensitive or moisture stable medical devices.

\section{Contraindications}

The following are contraindications for the use of ozone therapy.

- Recent Myocardial infarction

- Pregnancy

- Hyperthyroidism

- Active haemorrhage

- Glucose - 6 - phosphate - dehydrogenase deficiency (favism)

- $\quad$ Severe anaemia

- Acute alcohol intoxication

- Severe myasthenia.

\section{CONCLUSIONS}

As we all know that the dental treatment will step into a new phase of treatment post Covid-19, as practitioners we have to take utmost precautions during the dental procedures for the beneficiary of the dentist as well as the patients. This could include reduction of aerosols in all forms of dental treatment and replacing it with ozone therapy with continuous and regular follow up. Ozone therapy could be easily delivered worldwide, even in developing and very poor countries.

With few conventional treatments for viral pneumonia, this epidemic could provide impetus to study ozone therapy ethically under the auspices of an institution's review board in treating, with ozone therapy the seriously ill patients, who would otherwise expire. Milder cases could also be treated to study the ability of ozone therapy to slow or halt clinical deterioration. Such study could bring ozone therapy to the forefront of all infectious disease managements, providing answers to our growing problems with resistant infection.
Financial or other competing interests: None.

Disclosure forms provided by the authors are available with the full text of this article at jemds.com.

\section{REFERENCES}

[1] Harrel SK, Molinari J. Aerosols and splatter in dentistry: a brief review of the literature and infection control implications. J Am Dent Assoc 2004;135(4):429-37.

[2] Comisi JC, Ravenel TD, Kelly A, et al. Aerosol and spatter mitigation in dentistry: analysis of the effectiveness of 13 setups. J Esthet Restor Dent 2021;33(3):466-79.

[3] Nicola M, O'Neill N, Sohrabi C, et al. Evidence based management guideline for the COVID-19 pandemicreview article. Int J Surg 2020;77:206-16.

[4] Pattanaik B, Jetwa D, Pattanaik S, et al. Ozone therapy in dentistry: a literature review. Journal of Interdisciplinary Dentistry 2011;1(2):87-92.

[5] Nogales CG, Ferrari PH, Kantorovich EO, et al. Ozone therapy in medicine and dentistry. J Contemp Dent Pract 2008;9(4):75-84.

[6] Nagayoshi M, Kitamura C, Fukuizumi T, et al. Antimicrobial effect of ozonated water on bacteria invading dentinal tubules. J Endod 2004;30(11):778-81.

[7] Azarpazhooh A, Limeback H. The application of ozone in dentistry: a systematic review of literature. J Dent 2008;36(2):104-16.

[8] Huth KC, Jakob FM, Saugel B, et al. Effect of ozone on oral cells compared with established antimicrobials. Eur J Oral Sci 2006;114(5):435-40.

[9] Holmes J, Baysan A, Whiley RA, et al. Antimicrobial effect of novel ozone generating device. Carries Research 2004;39:4.

[10] Sechi LA, Lezcano I, Nunez N, et al. Antibacterial activity of ozonized sunflower oil (Oleozon). J Appl Microbiol 2001;90(2):279-84.

[11] Gupta G, Mansi B. Ozone therapy in periodontics. J Med Life 2012;5(1):59-67.

[12] Gupta S, Deepa D. Applications of ozone therapy in dentistry. Journal of Oral Research and Review 2016;8(2):86-91.

[13] Holmes J. Clinical reversal of root caries using ozone, double-blind, randomised, controlled 18-month trial. Gerodontology 2003;20(2):106-14.

[14] Baysan A, Lynch E. Effect of ozone on the oral microbiota and clinical severity of primary root caries Am J Dent 2004;17(1):56-60.

[15] Atabek D, Oztas N. Effectiveness of ozone with or without the additional use of remineralizing solution on noncavitated fissure carious lesions in permanent molars Eur J Dent 2011;5(4):393-9.

[16] Nagarakanti S, Athurulu D. Ozone: a new revolution in dentistry. Webmedcentral Dent 2011;2:1-5.

[17] Seidler V, Linetskiy I, Hubálkova H, et al. Ozone and its usage in general medicine and dentistry-a review article. Prague Med Rep 2008;109(1):5-13.

[18] Nagayoshi M, Fukuizumi T, Kitamura C. Efficacy of ozone on survival and permeability of oral microorganisms. Oral Microbiol Immunol 2004;19(4):240-6. 
[19] Maiya A. Applications of ozone in dentistry. International Journal of Clinical Dental Science 2011;2(3).

[20] Dahnhart JE, Jaeggi T, Scheidegger N, et al. Treating caries in anxious children with ozone: parents' attitudes after the first session. J Dent Res 2003;82:B265.

[21] Abu-Salem OT, Marashdeh MM, Lynch E. Ozone efficacy in treatment of occlusal caries in primary teeth. J Dent Res 2003;82:B136.

[22] Alpan AL, Bakar O. Ozone in dentistry. Ozone in Nature and Practice 2018.
[23] Ahmedi J, Ahmedi E, Sejfija 0, et al. Efficiency of gaseous ozone in reducing the development of dry socket following surgical third molar extraction. Eur J Dent 2016;10(3):381-5.

[24] Arita M, Nagayoshi M, Fukuizumi T, et al. Microbicidal efficacy of ozonated water against Candida albicans adhering to acrylic denture plates. Oral Microbiol Immunol 2005;20(4):206-10. 